\title{
Feasibility of a lifestyle intervention in early pregnancy to prevent deterioration of glucose tolerance
}

\author{
Eeva AL Korpi-Hyövälti ${ }^{*}$, David E Laaksonen ${ }^{2,3}$, Ursula S Schwab ${ }^{2,4}$, Tarja H Vanhapiha ${ }^{5}$, Kristiina R Vihla ${ }^{6}$,
} Seppo T Heinonen ${ }^{7}$ and Leo K Niskanen ${ }^{2}$

\begin{abstract}
Background: In conjunction with the growing prevalence of obesity and the older age of pregnant women gestational diabetes (GDM) is a major health problem.

The aim of the study was to evaluate if a lifestyle intervention since early pregnancy is feasible in improving the glucose tolerance of women at a high-risk for GDM in Finland.

Methods: A 75-g oral glucose tolerance test (OGTT) was performed in early pregnancy $(n=102)$. Women at high risk for GDM ( $n=54)$ were randomized at weeks 8-12 from Apr 2005 to May 2006 to a lifestyle intervention group $(n=27)$ or to a close follow-up group $(n=27)$. An OGTT was performed again at weeks $26-28$ for the lifestyle intervention and close follow-up groups.

Results: The values of the OGTT during the second trimester did not differ between the lifestyle intervention and close follow-up groups. In the lifestyle intervention group three women had GDM in the second trimester and respectively one woman in the close follow up group. Insulin therapy was not required in both groups. The intervention resulted in somewhat lower weight gain $11.4 \pm 6.0 \mathrm{~kg}$ vs. $13.9 \pm 5.1 \mathrm{~kg}, \mathrm{p}=0.062$, adjusted by the prepregnancy weight.
\end{abstract}

Conclusions: Early intervention with an OGT and simple lifestyle advice is feasible. A more intensive lifestyle intervention did not offer additional benefits with respect to glucose tolerance, although it tended to ameliorate the weight gain.

Trial Registration: ClinicalTrials.gov: NCT01130012

Keywords: gestational diabetes mellitus lifestyle intervention, oral glucose tolerance test, insulin treatment

\section{Background}

Management for women with gestational diabetes mellitus (GDM) consists of dietary counselling and physical exercise, and for those women who fail to maintain glycemic goals, insulin therapy [1]. Type 2 diabetes can be prevented or delayed by lifestyle changes, including increased physical activity, improvements in diet and modest weight loss in high-risk individuals $[2,3]$. There is little evidence demonstrating that GDM can be prevented by lifestyle changes in women at a high risk for GDM. Dempsey et al.

\footnotetext{
* Correspondence: eeva.korpi-hyovalti@epshp.fi

'Department of Internal Medicine, Seinäjoki Central Hospital, Seinäjoki, Finland

Full list of author information is available at the end of the article
}

found women most active within the first 20 weeks of pregnancy were half as likely to develop GDM [4].

GDM is defined as carbohydrate intolerance of varying severity with onset or first recognition during pregnancy [5,6]. Type 2 diabetes and GDM have similarities: both are characterized by a strong family history, overweight, insulin resistance, and lack of compensatory pancreatic insulin secretion in demanding hormonal circumstances $[7,8]$. GDM is usually diagnosed between $24-28$ weeks of pregnancy [9].

The occurrence of GDM varies from 2.2 to $8.8 \%$ depending on the diagnostic criteria used and population studied [10]. Like type 2 diabetes, the prevalence of GDM is increasing at an alarming rate worldwide [11].

\section{() Biomed Central}


There has been a long-standing controversy regarding whom and how to screen for GDM. Like many other European countries, Finland focuses screening on high-risk groups in the beginning of the third trimester 26-28 weeks [12-14].

We therefore carried out a randomized controlled trial in 54 pregnant women at high risk for GDM. We compared the effectiveness of early intensive lifestyle intervention to a single session lifestyle advice combined with a close follow-up. The hypothesis of this feasibility study was that early screening with an oral glucose tolerance test (OGTT) and lifestyle treatment since early pregnancy can improve glucose tolerance and decrease the incidence of GDM and related perinatal complications.

\section{Methods}

The study was an open multicenter randomized and controlled study with two rural municipalities: Kauhajoki and Lapua. The recruitment started in April 2005 and ended in May 2006. Deliveries occurred from Nov 2005 to Dec 2006. The protocol was approved by the ethics committee of South Ostrobothnia Hospital District in Seinäjoki, Finland. It was in accordance with Helsinki Declaration. All women participating in the trial gave written informed consent.

The health care nurses gave women counselling about healthy lifestyle in the beginning of pregnancy. The dietary and exercise advice were provided both verbally and in writing. Women were advised to stop alcohol intake and smoking.

\section{Randomisation}

A 2-hour OGTT was offered to all women in the first contact with maternal health care units during gestational weeks 8-12. If the women had one or more risk factors (BMI $>25 \mathrm{~kg} / \mathrm{m}^{2}$, previous history of GDM or birth of child $>4.5 \mathrm{~kg}$, age $>40$ years, family history of diabetes i.e. parents, children, siblings or grandparents) or the venous plasma glucose concentration after 12 hours fasting in the morning was $4.8-5.5 \mathrm{mmol} / \mathrm{l}$ and 2-hour OGTT plasma glucose $<7.8 \mathrm{mmol} / \mathrm{l}$, they were recruited to the intervention (Figure 1).

These high-risk women were randomly assigned to the lifestyle intervention group $(\mathrm{n}=27)$ or to the close follow-up group $(\mathrm{n}=27)$ by the study physician in the Central Hospital with the use of a computed randomisation list (Figure 1). We randomized 60 women, three dropped out (10\%) in each group (four early miscarriages, one twin pregnancy and one woman moved away). The health care nurses who scheduled the study visits did not have access to the randomisation list. We excluded women $(\mathrm{n}=14)$ who were diagnosed as having GDM in this study and women who had risk factors for GDM or whose fasting venous plasma glucose was
$4.8-5.5 \mathrm{mmol} / \mathrm{l}$ but who for personal or professional reasons did not wish to participate in the trial $(n=28)$. Obstetricians who were not study physicians made decisions concerning the beginning of insulin treatment, if the glucose targets were not achieved (fasting capillary glucose $>5.8 \mathrm{mmol} / \mathrm{l}$ or postprandial capillary glucose $>$ $8.5 \mathrm{mmol} / \mathrm{l}$ during self-monitoring, Figure 2).

\section{Diet counselling in the lifestyle intervention group}

Based on the general dietary recommendations of the Diabetes and Nutrition Study Group (DNSG) of European Association for the Study of Diabetes [15] for diabetes and the Finnish Diabetes Prevention Study [2], the goals of the diet in this study were carbohydrate 50-55 energy percent (E\%), fibre $15 \mathrm{~g} / 1000 \mathrm{kcal}$, fat $30 \mathrm{E} \%$, saturated fat $<10 \mathrm{E} \%$ and protein $15-20 \mathrm{E} \%$. Women were encouraged to eat a diet rich in vegetables, berries and fruits, and to use low-fat dairy products, low-fat meat, soft margarines and vegetable oils and wholegrain products. Recommendation for energy intake was $30 \mathrm{kcal} / \mathrm{kg} /$ day for normal weight women and $25 \mathrm{kcal} /$ $\mathrm{kg} /$ day for overweight women.

The nurse in the health care centres had on average 13 appointments with the intervention women. The intervention women had no instruction on self glucose monitoring before GDM was diagnosed. The nutritionist gave dietary advice tailored to each subject individually six times. The three-factor eating questionnaire was used in the beginning of pregnancy and at weeks 36-40 [16].

\section{Exercise counselling in the lifestyle intervention group}

We encouraged moderate-intensity physical exercise during pregnancy. The formula (220-age) $\times 0.65-0.75$ was used to estimate the heart rate goals for moderateintensity exercise [17]. Other measures of exercise intensity included the "talk test" [18], i.e. exercise at an intensity in which the woman is able to maintain a conversation during exercise. A target rating of 12 to 14 on Borg's scale of perceived exertion [19] was also used.

The pregnant women had six appointments with the physiotherapist. During sessions the physiotherapist motivated the women individually to continue exercising during pregnancy or to start exercising, and gave also written instructions for exercise and self care. When starting an aerobic exercise program, previously sedentary women were instructed to begin with 15 minutes of continuous exercise three times a week [20], increasing gradually to 30 minute sessions four times a week [21]. The goal of the exercise intervention was 30 minutes of daily physical activity, if the woman previously exercised $<2.5$ hours per week, and 45 minutes activity [22], if the woman already engaged in 2.5 hours or more per week of physical activity. Recommendable types of exercise were brisk walking, Nordic walking, swimming, cycling and 


\section{Early intervention $\mathrm{n}=102$ \\ OGTT $^{\mathrm{a}}$ at weeks $8-12$}

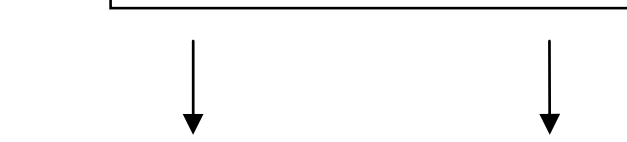

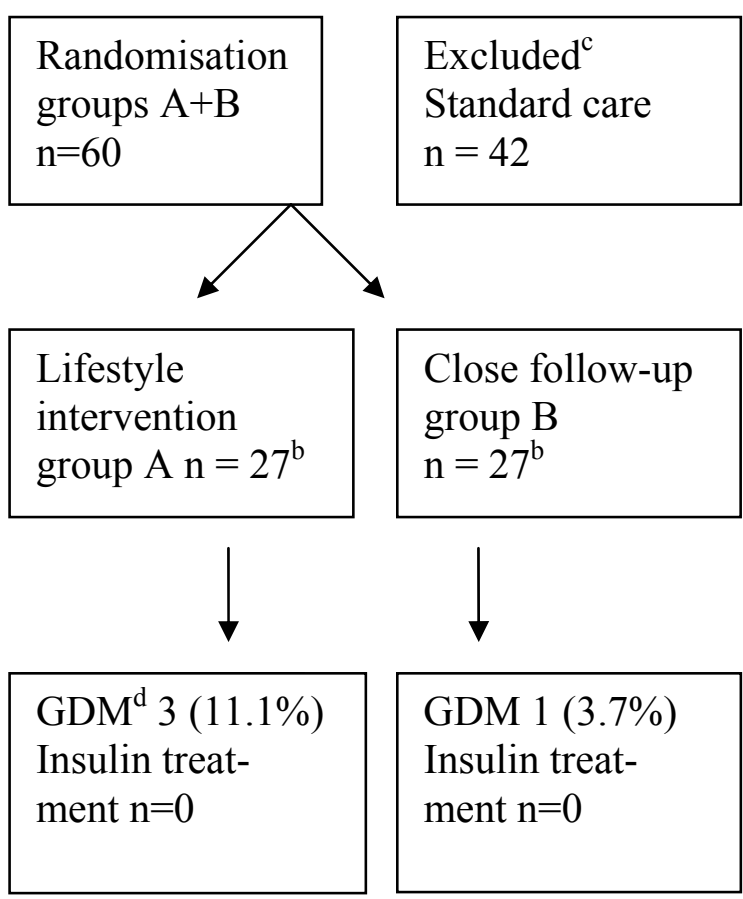

${ }^{\mathrm{a}}$ Oral glucose tolerance test. ${ }^{\mathrm{b}}$ Group A and B 30 women in the beginning: three dropped out (10\%) in each group, four early miscarriages, one twin pregnancy and one woman moved away. ${ }^{\mathrm{c}} 14$ women had GDM in the beginning, 28 women did not wish to participate in the intervention. ${ }^{\mathrm{d}}$ Gestational diabetes mellitus (fasting plasma glucose $\geq 5.6$ $\mathrm{mmol} / 1$ or 2-hour plasma glucose $\geq 7.8 \mathrm{mmol} / \mathrm{l}$ ).

Figure 1 Formation of the study populations.

cross country skiing [23]. If the BMI of a woman was > $30 \mathrm{~kg} / \mathrm{m}^{2}$ and the woman was not physically active before pregnancy, the exercise was started with 15 minutes per day three times a week $[20,22]$. Women were offered both aerobics classes and aquafit classes weekly.

\section{Close follow-up group}

The women were informed of the results of the OGTT during gestational weeks 8-12. All women were also given general information on diet and physical activity to decrease the risk of GDM during pregnancy. Dietary information was collected three times during pregnancy. They returned a self reported exercise history and a monthly questionnaire of physical activity. Otherwise, the women were followed up in the prenatal clinic of the municipal health centre at one-month intervals according to standard care in Finland (Figure 2) [24].

\section{Definition of GDM}

The GDM criteria were modified from the World Health Organization as a fasting plasma glucose $5.6 \mathrm{mmol} / \mathrm{l}$ or 2 -hour plasma glucose $7.8 \mathrm{mmol} / \mathrm{l}$ [6]. 


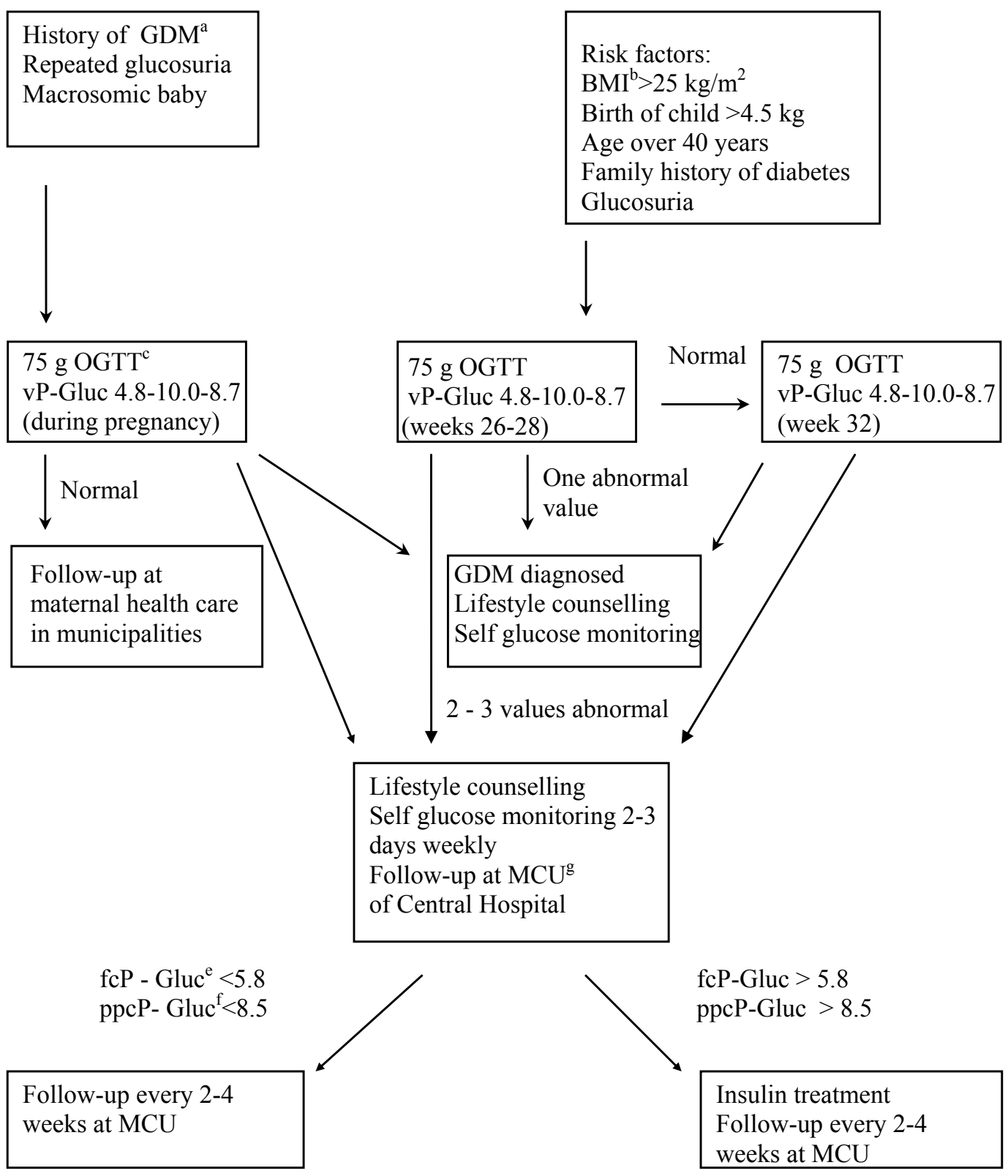

${ }^{\mathrm{a}}$ Gestational diabetes mellitus, ${ }^{\mathrm{b}}$ Body-mass index, ${ }^{\mathrm{c}}$ Oral glucose tolerance test, ${ }^{\mathrm{d}}$ venous plasma glucose, ${ }^{\mathrm{e}}$ fasting capillary plasma glucose, ${ }^{\mathrm{f}}$ post prandial capillary plasma glucose,

${ }^{\mathrm{g}}$ Maternal care unit

Figure 2 Screening and follow-up of the gestational diabetes in Finland 2005.

\section{Screening for GDM}

A 2-hour OGTT containing 75 g glucose was offered to all women in the early intervention groups during gestational weeks 8-12 (Table 1). The OGTT was repeated during gestational weeks 26-28.

\section{Examinations}

A nurse measured height, weight, and blood pressure of women at the first appointment during gestational weeks 8-12. Blood pressure was measured twice on the right arm with the subject in a sitting position after 
Table 1 Research design and methods

\begin{tabular}{|c|c|c|}
\hline $\begin{array}{l}\text { Counselling and } \\
\text { follow-up }\end{array}$ & $\begin{array}{l}\text { Lifestyle intervention } \\
(\mathrm{n}=27)^{\mathrm{a}}\end{array}$ & $\begin{array}{l}\text { Close follow-up } \\
(\mathrm{n}=27)^{\mathrm{a}}\end{array}$ \\
\hline $\begin{array}{l}\text { Lifestyle counselling } \\
\text { (nurse) }\end{array}$ & + & + \\
\hline$\overline{\mathrm{OGTT}}$ (weeks 8-12) & + & + \\
\hline$S G M^{c}$ & - & - \\
\hline Diet reporting $^{d}$ & 3 times & 3 times \\
\hline$\overline{\text { TFEQ }^{e}}$ & 2 times & 2 times \\
\hline $\begin{array}{l}\text { Counseling(clinical } \\
\text { nutritionist) }\end{array}$ & 6 times & - \\
\hline Exercise history & + & + \\
\hline $\begin{array}{l}\text { Exercise reporting diaries } \\
\text { monthly }\end{array}$ & 6 times & 6 times \\
\hline $\begin{array}{l}\text { Exercise counselling } \\
\text { (physiotherapist) }\end{array}$ & $\begin{array}{l}6 \text { times, twice in } \\
\text { groups }\end{array}$ & - \\
\hline OGTT (weeks 26-28) & + & + \\
\hline $\begin{array}{l}\text { GDMf-counselling (nurse) } \\
\text { and SGM }\end{array}$ & + & + \\
\hline \multicolumn{3}{|c|}{$\begin{array}{l}\text { a60 women randomized in the beginning: three dropped out }(10 \%) \text { in each } \\
\text { group ( } 4 \text { early miscarriages, one twin pregnancy and one woman moved } \\
\text { away). }\end{array}$} \\
\hline${ }^{\mathrm{b}}$ Oral glucose tolerance test. & \multicolumn{2}{|c|}{ 'Self glucose monitoring. } \\
\hline \multicolumn{3}{|c|}{$\begin{array}{l}\text { d } 4 \text {-day food records at baseline, at weeks } 26-28 \text { and in the end of pregnancy. } \\
{ }^{\text {T}} \text { The three-factor eating questionnaire [16]. }\end{array}$} \\
\hline${ }^{\mathrm{f} G e s t a t i o n a l ~ d i a b e t e s ~ m e l l i t u ~}$ & & \\
\hline
\end{tabular}

10 min of rest, using a standard automatic sphygmomanometer. Newborns and placentae were weighed immediately after delivery. The data of singleton pregnancies and deliveries were extracted from the medical records in maternal health care units and in the Central Hospital of Seinäjoki.

A $75 \mathrm{~g}$ 2-hour oral glucose tolerance test after overnight fasting for 12 hour was performed at gestational weeks 8-12 and at weeks 26-28 with measurement of plasma glucose at 0,1 and 2 hours. Plasma glucose was determined immediately with a photometric hexokinase assay from samples drawn into a fluoride-citrate tube (Abbot Laboratories, Abbot Park IL) in the Central Hospital of Seinäjoki.

\section{Statistical analysis}

Statistical analyses were based on the intention to treat. The final analyses were conducted using SPSS for Windows version 15.0 (SPSS Inc, Chicago, Illinois). Differences between the groups were analysed by Student's t-test for continuous variables, and the chi-square test and Fisher's exact test for categorical variables. Statistical significance was set at the $95 \%$ level $(\mathrm{p}<0.05)$.

\section{Results}

\section{Baseline characteristics of the study groups}

There were no statistically significant differences in baseline measures between the lifestyle intervention $(\mathrm{n}=27)$ and the close follow-up $(\mathrm{n}=27)$ groups (Table 2).

\section{Glucose tolerance at weeks $\mathbf{2 6 - 2 8}$}

There was no difference between the randomized groups in the change in glucose values from baseline to gestational weeks 26-28 during the 2-hour OGTT. There was also no difference between the randomized groups in glucose tolerance at weeks 26-28. GDM was diagnosed in three of the lifestyle intervention group and in one of the close follow-up group. None of them required insulin therapy (Table 3).

\section{Maternal outcomes}

The intervention resulted in somewhat lower weight gain during pregnancy $(11.4 \pm 6.0 \mathrm{~kg}$ vs. $13.9 \pm 5.1 \mathrm{~kg}$, $\mathrm{p}=0.062$, adjusted by the prepregnancy weight).

There was no statistically significant difference between the randomised groups in terms of pre-eclampsia, induction of labor, lacerations, Cesarean deliveries (data not shown).

\section{Newborn outcomes}

The mean birth weight was greater $3871 \pm 567 \mathrm{~g}$ in the lifestyle intervention group $(\mathrm{p}=0.047$, adjusted by the prepregnancy weight of the women) compared with the close follow-up group $3491 \pm 573 \mathrm{~g}$. The mean birth weight was $3564 \mathrm{~g}$ in the period 1996-2000 in Finland [25]. There was no difference in macrosomia $(\mathrm{p}=0.480$, adjusted by the prepregnancy weight of the women) between the groups.

There was no statistically significant difference between the randomized groups in terms of gestational age, admissions to neonatal intensive care unit, jaundice requiring phototherapy or respiratory distress (data not shown).

\section{Discussion}

Early intervention with an OGTT and lifestyle advice in high-risk mothers is feasible. More intensive lifestyle advice was not more effective than close follow-up. However, weight gain during pregnancy tended to be lower in the intensive group. The rate of neonatal complications in the study groups was similar.

Somewhat surprisingly, the intensive lifestyle intervention and the close follow-up were equally effective with respect to glucose tolerance and GDM in the current study. High-risk pregnant women may be particularly receptive to lifestyle advice. On the other hand a part of women are not able to change their lifestyle or the maintenance of applied eating or physical activity habits are short sighted even during pregnancy. Small group differences at randomization may also have affected the results. Prepregnancy weight in the lifestyle intervention 
Table 2 Baseline characteristics of the women (mean \pm SD or numbers, percentage in parentheses)

\begin{tabular}{|c|c|c|c|}
\hline Characteristic & $\begin{array}{l}\text { Lifestyle intervention } \\
n=27\end{array}$ & $\begin{array}{l}\text { Close follow-up } \\
n=27\end{array}$ & p value ${ }^{a}$ \\
\hline Age & $29.1 \pm 5.4$ & $29.8 \pm 5.4$ & NS \\
\hline Primiparous & $13(50)$ & $17(63)$ & NS \\
\hline Body-mass index $\left(\mathrm{kg} / \mathrm{m}^{2}\right)$ & $27.3 \pm 6.0$ & $25.5 \pm 3.4$ & NS \\
\hline Prepregnancy weight $(\mathrm{kg})$ & $76.6 \pm 16.1$ & $69.6 \pm 9.7$ & 0.061 \\
\hline Previous Cesarean delivery & $3(12)$ & $1(3.7)$ & NS \\
\hline Risk factors & $25(86.2)$ & $21(72.4)$ & NS \\
\hline $\mathrm{BMI}>25\left(\mathrm{~kg} / \mathrm{m}^{2}\right)$ & $18(60)$ & $17(56.7)$ & NS \\
\hline Previous birth of child $>4.5 \mathrm{~kg}$ & 0 & $1(3.4)$ & NS \\
\hline Age $>40$ years & 0 & $1(3.3)$ & NS \\
\hline Previous history of GDM & $5(16.7)$ & $1(3.4)$ & NS \\
\hline Family history of diabetes & $13(43.3)$ & $12(41.4)$ & NS \\
\hline Prepregnancy smoking & $1(3.7)$ & $2(7.4)$ & NS \\
\hline Higher educational status & $5(18.5)$ & $12(44.4)$ & 0.080 \\
\hline Office or service work & $13(46.4)$ & $18(64.3)$ & NS \\
\hline Fasting glucose (mmol/l) & $5.0 \pm 0.3$ & $4.9 \pm 0.3$ & NS \\
\hline OGTT 1-hour glucose $(\mathrm{mmol} / \mathrm{l})$ & $6.4 \pm 1.4$ & $6.0 \pm 1.1$ & NS \\
\hline OGTT 2-hour glucose $(\mathrm{mmol} / \mathrm{l})$ & $5.6 \pm 1.0$ & $5.4 \pm 1.0$ & NS \\
\hline Area under the curve $(\mathrm{mmol} / \mathrm{l} / 2 \mathrm{~h})$ & $11.7 \pm 1.7$ & $11.2 \pm 1.5$ & NS \\
\hline Systolic blood pressure $(\mathrm{mmHg})$ & $117.3 \pm 10.3$ & $119.4 \pm 8.9$ & NS \\
\hline Diastolic blood pressure $(\mathrm{mmHg})$ & $72.9 \pm 7.9$ & $70.9 \pm 7.4$ & NS \\
\hline
\end{tabular}

${ }^{a} p$ value: Student's t-test for independent samples, chi-square or Fisher's exact test.

group tended to be higher compared with the close follow-up group, and all women weighing over $100 \mathrm{~kg}$ were in the intervention group. The women in the close follow-up group tended to have a higher educational status $(\mathrm{p}=0.080)$.

Few studies have assessed the role of intervention early in pregnancy on the prevention or treatment of GDM. In the study by Bartha et al. women with an early diagnosis and treatment of gestational diabetes represented a high-risk group with a worse prognosis regarding pregnancy complications and outcomes [26]. Callaway recruited 25 obese women at 12 weeks' gestation in a randomized controlled study. They received an individualized exercise program with an energy expenditure (EE) goal of $900 \mathrm{kcal} /$ week. This intervention was feasible and prompted a modest increase in physical activity [27]. The study was underpowered to detect an effect on GDM.

We used GDM criteria modified from the WHO definition (fasting plasma glucose $5.6 \mathrm{mmol} / \mathrm{l}$ or 2-hour glucose $7.8 \mathrm{mmol} / \mathrm{l}$ ) [6]. Interestingly, we found 14 cases of GDM already in the beginning of pregnancy, suggesting that they had prepregnancy impairment of glucose metabolism. Treatment for GDM was initiated in early

Table 3 Weight gain, oral glucose tolerance test at weeks 26-28 and requirement of insulin therapy (mean \pm SD or numbers, percentage in parentheses)

\begin{tabular}{lll}
\hline Outcomes & Lifestyle intervention group $\mathbf{n}=\mathbf{2 7}^{\mathbf{a}}$ & Close follow-up group $\mathbf{n}=\mathbf{2 7}^{\mathbf{p} \text { value } \mathbf{b}}$ \\
\hline Total weight gain $(\mathrm{kg})$ & $11.4 \pm 6.0$ & $13.9 \pm 5.1$ \\
\hline Weight at the end of pregnancy $(\mathrm{kg})$ & $88.6 \pm 14.4$ & $84.1 \pm 11.3$ \\
\hline Fasting glucose $(\mathrm{mmol} / \mathrm{l})$ & $4.6 \pm 0.4$ & $4.4 \pm 0.3$ \\
\hline OGTT 1-hour glucose $(\mathrm{mmol} / \mathrm{l})$ & $6.9 \pm 1.7$ & $6.9 \pm 1.7$ \\
\hline OGTT 2-hour glucose $(\mathrm{mmol} / \mathrm{l})$ & $6.1 \pm 1.4$ & $6.0 \pm 1.2$ \\
\hline Area under the curve $(\mathrm{mmol} / \mathrm{l} / 2 \mathrm{~h})$ & $12.3 \pm 2.4$ & $12.1 \pm 2.2$ \\
\hline Gestational diabetes & $3(11.1)$ & $1(3.7)$ \\
\hline Insulin therapy & 0 & 0 \\
\hline
\end{tabular}

${ }^{a}$ An OGTT was carried out in 26 (96.3\%) women in the lifestyle intervention group.

b value: Student's t-test for independent samples or Fisher's exact test was used. 
pregnancy for these women, and four normalized their glucose tolerance and only three required insulin therapy later in their pregnancy. The prevalence of GDM was $12.0 \%(31 / 258)$ in study municipalities and at the same time period in two neighboring municipalities without early intervention $14.5 \%(26 / 181)$. The difference was greater concerning the treatment with insulin: $2.3 \%(6 / 258)$ of pregnant women in study municipalities had insulin treatment compared with $8.3 \%(15 / 181)$ of women with the standard care. Screening of glucose tolerance among high-risk, especially overweight women and lifestyle advice in early pregnancy may be an effective way to improve glucose tolerance in high-risk women in later pregnancy.

When an OGTT is performed very early in the pregnancy it is worth noting, that fasting glucose concentrations reach their nadir at 12 weeks of gestation and remain at this level until delivery [28].

The encouraging finding was that the intervention resulted in somewhat, albeit not statistically significantly lower weight gain as compared with the close follow-up group. However, the prepregnancy weight tended to be higher $(\mathrm{p}=0.061)$ in the intervention group than in the close follow-up group. Obese women on average gain less weight during pregnancy than women with normal weight [29]. In the analyses, however, we adjusted for prepregnancy weight. In Finland, the mean weight gain during pregnancy has increased from $13.3 \mathrm{~kg}$ in 1960 to $14.3 \mathrm{~kg}$ in 2000 [30]. In the same period the prepregnancy weight has increased from $57.6 \mathrm{~kg}$ to $65.5 \mathrm{~kg}$ [30]. In the study municipalities the prepregnancy weight was $69.1 \pm 15.1 \mathrm{~kg}$.

In large cohorts of pregnant women, there has been a continuous relationship between mother's glycemia and newborn birth weight below standard cut-off levels for GDM [31,32]. Our study group is too small to conclude from pregnancy outcomes.

One of the strengths of this feasibility study is that it was performed in a community-based setting in a rural area, and the intervention was conducted with little or no extra resources. Although the results of the study were encouraging, there were obvious weaknesses. First, the study had a relatively small number of participants. Second, the interventions seemed to be so "effective" that the number of cases of GDM in the randomized groups of high-risk women was very small, only four out of 54 women. Third we had no international consensus of criteria for GDM in the year 2005. Finnish threshold value, especially the fasting glucose $4.8 \mathrm{mmol} / \mathrm{l}$, for the diagnosis of GDM was too low in early pregnancy. This is the reason why we used the modified WHO definition for the early intervention groups. This complicated the study setting. This study was carried out as a feasibility study. The results should be viewed against this background and need to be corroborated in larger studies.

\section{Conclusions}

In this community-based intervention study, our findings suggest that early intervention with an OGTT and simple lifestyle advice is feasible. More intensive lifestyle intervention does not seem to have marked additional benefits. Concentration on high-risk, especially overweight women may be important and useful. Larger trials are nonetheless needed.

\section{Abbreviations}

AUC: area under the curve; BMI: body mass index; GDM: gestational diabetes mellitus; DNSG: Diabetes and Nutrition Study Group; DPS: Diabetes

Prevention Study; EASD: European Association for the Study of Diabetes; EE: energy expenditure; E\%: Energy percent; fcP-Gluc: fasting capillary plasma glucose; HAPO: Hyperglycemia and Adverse Pregnancy Outcomes; MCU: Maternal Care Unit; NICU: Neonatal Intensive Care Unit; OGTT: oral glucose tolerance test; ppcP-Gluc: post prandial capillary plasma glucose; SGM: self glucose monitoring; vP-Gluc: venous plasma glucose; WHO: World Health Organization

\section{Acknowledgements}

This study was funded by Seinäjoki Central Hospital and Kuopio University Hospital, University of Eastern Finland and municipalities of Kauhajoki, Lapua i.e. employers of the authors mentioned on the title page. The study was supported by EVO funding from Kuopio University Hospital and South Ostrobothnia Hospital District.

\section{Author details}

'Department of Internal Medicine, Seinäjoki Central Hospital, Seinäjoki, Finland. ${ }^{2}$ Department of Medicine, Kuopio University Hospital, Kuopio, Finland. Institute of Biomedicine, Physiology, University of Eastern Finland, Kuopio Campus, Finland. ${ }^{4}$ Department of Clinical Nutrition, School of Public Health and Clinical Nutrition, University of Eastern Finland, Kuopio Campus, Finland. ${ }^{5}$ Kauhajoki Health Center Social Welfares, Kauhajoki, Finland. ${ }^{6}$ Lapua Health Center, Lapua, Finland. 'Department of Obstetrics and Gynecology, Kuopio University Hospital, Finland.

\section{Authors' contributions}

EK-H participated in the design of the study, acquisition of the data, performed the statistical analysis and drafted the manuscript. DEL, LN, US and SH had substantial contributions to conception and design of the study and they helped to draft the manuscript. TV and KV participated in data collection. All authors read and approved the final manuscript.

\section{Competing interests}

The authors declare that they have no competing interests.

Received: 8 December 2010 Accepted: 24 March 2011

Published: 24 March 2011

\section{References}

1. Metzger BE, Buchanan TA, Coustan DR, de Leiva A, Dunger DB, Hadden DR, Hod M, Kitzmiller JR, Kjos SL, Oats JN, Pettitt DJ, Sacks DA, Zoupas C: Summary and recommendations of the fifth international workshop-conference on gestational diabetes mellitus. Diabetes Care 2007, 30:5251-60.

2. Tuomilehto J, Lindström J, Eriksson JG, Valle T, Hämäläinen $H$, llanneParikka P, Keinänen-Kiukaanniemi S, Laakso M, Louheranta A, Rastas M, Salminen $V$, Uusitupa M: Prevention of type 2 diabetes mellitus by changes in lifestyle among subjects with impaired glucose tolerance. $N$ Engl J Med 2001, 344:1343-50.

3. Diabetes Prevention Program Research Group: Reduction in the incidence of type 2 diabetes with lifestyle intervention or metformin. $N$ Engl I Med 2002, 346:393-403.

4. Dempsey JC, Butler CL, Sorensen TK, Lee IM, Thompson ML, Miller RS, Frederick IO, Williams MA: A case control study of maternal recreational physical activity and risk of gestational diabetes mellitus. Diab Res Clin Pract 2004, 66:203-15. 
5. Metzger BE and the Organizing Committe: Summary and recommendations of the Third International Workshop-Conference of Gestational Diabetes Mellitus. Diabetes 1991, 40(Suppl 2):197-201.

6. Alberti KG, Zimmet PZ: Definition, diagnosis and classification of diabetes mellitus and its complications. Part 1: diagnosis and classification of diabetes mellitus: provisional report of WHO consultation. Diabet Med 1998, 15:539-53.

7. Metzger BE, Freinkel N: Effects of diabetes mellitus in the endocrinologic and the metabolic adaptation of gestation. Semin Perinatol 1978, 2:309-18.

8. Jovanovic-Peterson L, Peterson M: Review of Gestational Diabetes Mellitus and Low-calorie Diet and Physical Exercise as Therapy. Diabetes/ Metabolism Reviews by John Wiley \& Sons, Ldt 1996, 12(4):287-308.

9. Metzger BE, Coustan DR: Summary and recommendations of the Fourth International Workshop-Conference on gestational diabetes mellitus. Diabetes Care 1998, 21(Suppl 2):B161-7.

10. Cheung NW, Byth K: Population health significance of gestational diabetes. Diabetes Care 2005, 26:2005-9.

11. Dabelea D, Snell-Bergeon JK, Hartsfield CL, Bischoff KJ, Hamman RF, McDuffie RS: Increasing prevalence of gestational diabetes mellitus (GDM) over time and by birth cohort. Diabetes Care 2005, 28:579-84.

12. Guttorm E: Practical screening for diabetes mellitus in pregnant women. Acta Endocrinol 1974, 75:11-24.

13. Jensen DM, Mølsted-Pederse L, Beck-Nielsen H, Westergaard JG, Ovesen P, Damm P: Screening for gestational diabetes mellitus by a model based on risk indicators: A prospective study. Am J Obstet Gynecol 2003, 189:1383-8.

14. Schaefer-Graf UM, Pawliczak J, Passow D, Hartman R, Rossi R, Bührer C, Harder T, Plagemann A, Vetter K, Kordonouri O: Birth weight and parenteral BMI predict overweight in children from mothers with gestational diabetes. Diabetes Care 2005, 28:1745-50.

15. The Diabetes and Nutrition Study Group (DNSG) of the European Association for the Study of Diabetes (EASD): Recommendations for the nutritional management of patients with diabetes mellitus. Eur J Clin Nutr 2000, 54:353-5.

16. Stunkard AJ, Messick S: The three-factor eating questionnaire to measure dietary restaint, disinhibition and hunger. J Psychosom Res 1985, 29:71-83.

17. Davies GAL, Wolfe LA, Mottola MF, MacKinnon C: Joint SOGC/CSEP Clinical Practice Guidline: Exercise in pregnancy and the postpartum period. Can J Appl Physiol 2003, 28(3):329-341, Canadian Society for Exercise Physiology.

18. Ohtake PJ, Wolfe LA: Physical conditioning attenuates respiratory responses to steady-state exercise in late gestation. Med Sci Sports Exerc 1998, 30:17-27.

19. Borg GA: Physical performance and perceived exertion. DhD Thesis Lund University; 1962.

20. Bung $P$, Bung $C$, Artal R, Khodiguian N, Fallenstein F, Spätling L: Therapeutic exercise for insulin-requiring gestational diabetics: effects on the fetus results of a randomized prospective longitudinal study. J Perinat Med 1993, 21:125-37.

21. Campbell MK, Mottola MF: Recreational exercise and occupational activity during pregnancy and birth weight: A case control study. Am J Obstet Gynecol 2001, 184:403-8.

22. Soultanakis HN, Artal R, Wiswell RA: Prolonged Exercise in pregnancy: Glucose homeostasis, ventilatory and cardiovasklar responses. Seminars in Perinatol 1996, 20:315-27.

23. Hartmann S, Bung P: Physical exercise during pregnancy physiological considerations and recommendations. J Perinat Med 1999, 27:204-15.

24. Suomen Diabetesliiton työryhmä (in Finnish): Gestaatiodiabetes. Suomen Lääkärilehti 1993, 48(26):2451-4

25. Mortensen LH, Diderichsen F, Amtzen A, Gissler M, Cnattingius S, Schnor O, Davey-Smith G, Nybo Andersen A-M: Social inequality in fetal growth: a comparative study of Denmark, Finland, Norway and Sweden in the period 1981-2000. J Epidemiol Community Health 2008, 62:325-331.

26. Bartha JL, Martinez-Del-Fresno P, Comino-Delgado R: Gestational diabetes mellitus diagnosed during early pregnancy. Am J Obstet Gynecol 2000, 182:346-50.

27. Callaway LK, Colditz PB, Byrne NM, Lingwood BE, Rowlands IJ, Foxcroft K, McIntyre HD, for the Bambino Group: Prevention of Gestational Diabetes. Feasibility issues for an exercise intervention in obese pregnant women. Diabetes Care 2010, 33:1457-1459.

28. Lind T, Aspillaga M: Metabolic changes during normal and diabetic pregnancies. From Diabetes mellitus in pregnancy. In Principals and practise. Edited by: Reece EA, Coustan DR. New York: Churchill Livingston; 1988.

29. Carmichael S, Abrams B, Selvin S: The pattern of maternal weight gain in women with good pregnancy outcomes. Am J Public Health 1997, 87:1984-8

30. Kinnunen TI, Luoto R, Gissler M, Hemminki E: Pregnancy weight gain from 1960s to 2000 in Finland. International Journal of Obesity 2003, 27:1572-7.

31. Sermer M, Naylor CD, Care DJ, Kenshole AB, Ritchie JWK, Farine D, Cohen HR, McArthur K, Holzapfel S, Biringer A, Chen E: Impact of increasing carbohydrate intolerance on maternal-fetal outcomes in 3637 women without gestational diabetes. Am J Obstet Gynecol 1995, 173:146-56.

32. The HAPO Study Cooperative Research Group: Hyperglycemia and Adverse Pregnancy Outcomes. N Engl J Med 2008, 358:1991-2002.

\section{Pre-publication history}

The pre-publication history for this paper can be accessed here: http://www.biomedcentral.com/1471-2458/11/179/prepub

doi:10.1186/1471-2458-11-179

Cite this article as: Korpi-Hyövälti et al:: Feasibility of a lifestyle intervention in early pregnancy to prevent deterioration of glucose tolerance. BMC Public Health 2011 11:179.

\section{Submit your next manuscript to BioMed Central and take full advantage of:}

- Convenient online submission

- Thorough peer review

- No space constraints or color figure charges

- Immediate publication on acceptance

- Inclusion in PubMed, CAS, Scopus and Google Scholar

- Research which is freely available for redistribution

Submit your manuscript at www.biomedcentral.com/submit
C Biomed Central 